\title{
The Littoral Station of Aguda, in the North of Portugal
}

\author{
M. Weber \\ Instituto de Ciências Biomédicas; Largo do Prof. Abel Salazar 2, P-4000 Porto, Portugal
}

\begin{abstract}
The public authorities have recently approved the building of a Littoral Station in Aguda, a small fishing village on the Atlantic coast, $15 \mathrm{~km}$ south of the River Douro estuary in the municipal area of Vila Nova de Gaia. The internal structure of the building involves a $F$ is h e ry Museum exhibiting ancient and modern gear, a Public Aquarium displaying the local marine fauna and flora and a Research and Educational Department for marine biology, aquaculture and fishery. The project was drawn up by the architect Joano Paulo Peixoto, in collaboration with local engineers, and the author. In Aguda there is an active, small-scale fishery, based on traditional methods handed down from generation to generation. The almost unstudied local marine fauna and flora is characterized by a high diversity of invertebrates and a rich abundance of fish stocks. Easy access to a variety of marine biotopes is guaranteed by means of the local fishing-fleet, thus supporting the Station's programme of education and research.
\end{abstract}

\section{INTRODUCTION}

In 1988, the idea of a Littoral Station at Praia da Aguda was proposed to the town council of Vila Nova de Gaia, who considered it to be highly worthy of support and an excellent investment under cultural, scientific and touristic aspects. The project is funded by the Portuguese Government/Secretary of Tourism. The construction of the building will start late in 1992 and the inauguration is planned for 1995. The Station is justified by the absence of local educational and scientific facilities and by a lack of tourist attractions. Also little knowledge about the structure and dynamics of local littoral ecosystems, increasing pollution, and a growing interest in marine biology at the Institute of Biomedical Sciences of the University of Porto, encouraged the development of the project. Earlier attempts to create a public aquarium as an educational institution in the area of Porto (Weber, 1989) were discouraged because of financial problems.

Characterized by a rich plankton productivity, owing to upwelling and a high diversity of marine fishes and invertebrates, the shoreline of Vila Nova de Gaia can be considered as a complex of very productive, unstudied ecosystems. The rocky coast at Praia da Aguda is flat and completely exposed to the open sea. The mean tide varies by approximately 3.5 metres. The zonation patterns of the littoral consist of musselbanks (Mytilus edulis f. galloprovincialis), tidepools with calcareous algae (Lithophyllum incrustans), polychaete reefs (Sabellaria alveolata) and dense colonies of brown macroalgae (Saccorhiza polyschides, Laminaria digitata). At greater depths, large sand banks are populated by Spisula solida. 


\section{THE “ARTESANAL" FISHERY AT PRAIA DA AGUDA}

Portugal owns one of the largest Exclusive Economic Zones in Europe. The smallscale fishery, carried out in an area of only $6 \%$ of the zone, still has a great social importance for the majority of the littoral communities.

Praia da Aguda is one of the 51 fishing ports on the Portuguese coast. The place is named after a sharp rock which emerges from the sea - and it is here where local fishermen originally constructed their wooden houses at the end of the last century. Their catch consisted mainly of swimcrabs (Polybius henslowi) which were sold entirely to the farmers of the area for fertilizers. Today the community numbers about 500 people, of whom $20 \%$ are involved actively in the "artesanal" fishery. About $35 \%$ of the fishermen are under 40 years old, more than $50 \%$ completed only the fourth class of primary school, and $10 \%$ are illiterate.

Traditional fishing arts, manufacture and repair of gear and boats were handed down from generation to generation (Weber \& Bleicker, 1991). The wooden boats of 7.5 metres length are multipurpose, with a variety of fishing gear such as entangling and gill nets, longlines, pots, dredges and trolling equipment. Their usage changes with the occurrence of species, the success gained with each method, the meteorological conditions and the season of the year. Periods of intense labour alternate with underoccupation.

The fishing takes place along the coast between the Douro estuary and Espinho, in an area $6-8 \mathrm{sm}$ wide and 35 to 40 metres deep. Economically, the most representative species are seabasses (Dicentrarchus labrax), pouts (Trisopterus luscus), shrimps (Palaemon serratus), congereels (Conger conger) and through shells (Spisula solida). Owing to the exposed nature of the coastline, the rough weather, the difficult working conditions and the high rate of accidents, increasing numbers of fishermen are leaving their profession to enter safer and better paid jobs in industry and civil construction. Consequently, the fleet declines from year to year.

Among the social and economic problems encountered are low and irregular income, poor housing conditions, a low literacy level, high emigration rate and a lack of professional training for young people. Until recently, education was linked to the basic system of the community, the family being the only source of information. A few years ago a Fishery School "Forpescas" was set up in Matosinhos, giving access to professional training courses in fishery disciplines. This has increased the awareness of safety provisions on board boats.

In any case, the decline of the fishing activity at Aguda's Beach can only be arrested by improving working conditions, safety, equipment, social welfare provisions, education and information to the fishing community.

\section{LOCALIZATION}

Several criteria for the choice of the Station's building ground have been taken into account - such as shore position (for an easy supply of sea water), existence of active small-scale fishing, urban and environmental integration, ease of access and parking provision in the area and security considerations (Fig. 1).

At present, the ground consists of sand with a rocky substrate. Sediments are deposited by wind and sea during the winter storms - a situation which is to be altered by 


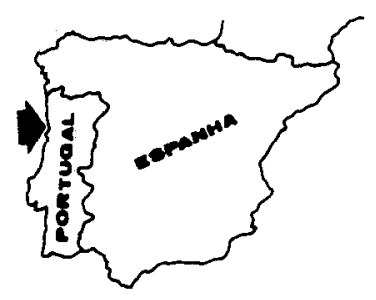

praia

Da

acuda
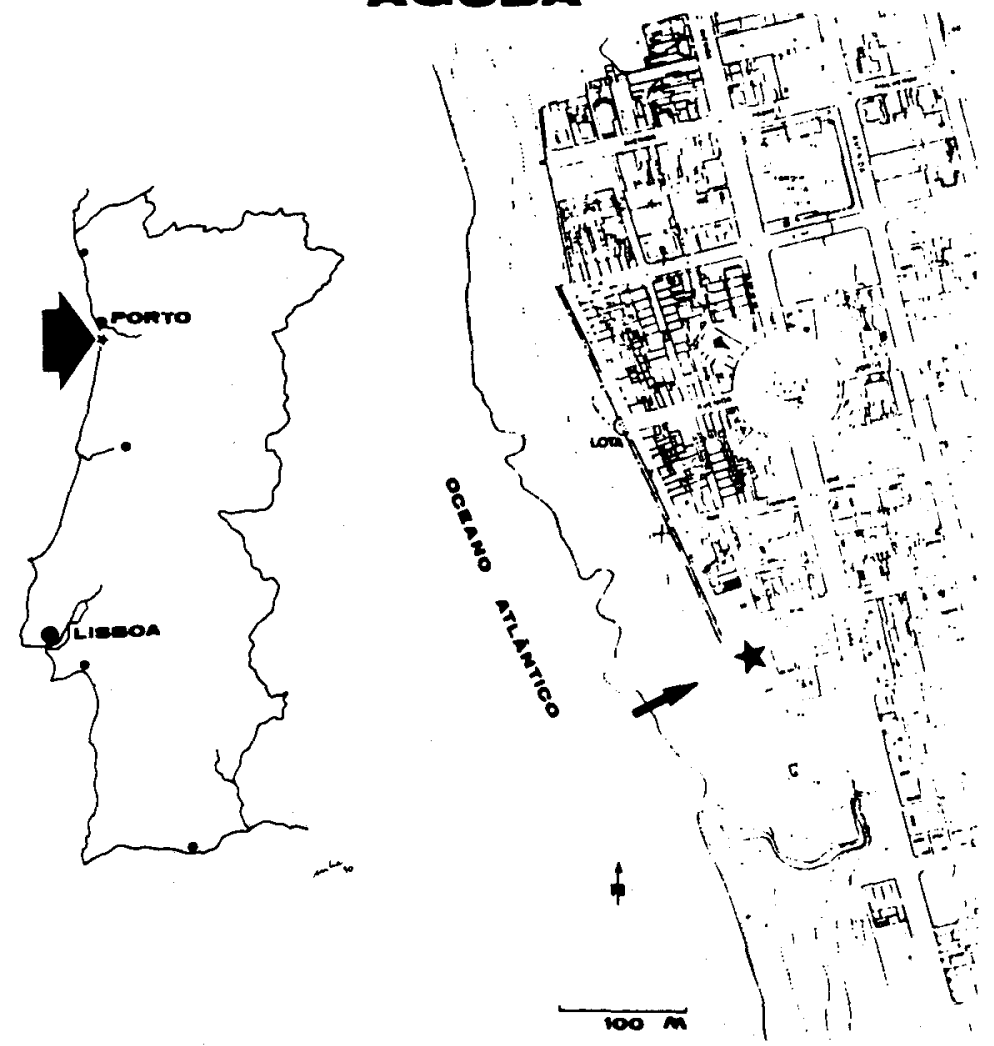

Fig. 1. Location of the Littoral Station at Praia da Aguda 
the construction of two breakwaters, a project for which the fishermen of Aguda have been waiting since 1936 .

\section{INTERNAL STRUCTURE AND FUNCTION}

The building has been designed to integrate the following departments (Fig. 2):

a Fishery Museum, displaying ancient and up-to-date equipment from all over the world, including a part of the private collection of Prof. Dr. Andres von Brandt, long-term head of Hamburg's Materials and Gear Section of the Federal Research Board of Fisheries in Germany;

a Public Aquarium, exhibiting the local marine fauna and flora in 15 display tanks, supplied with cooled sea water from a semi-closed system;

and a Research and Educational Department for marine biological disciplines, aquaculture and fishery biology, providing study facilities for students, researchers and fishermen.

The construction is divided into a public zone comprised of the Fishery Museum and the Aquarium, surrounded by a service zone where the Research and Educational Department is located.

Owing to its proximity to the sea, and the prevailing atmospheric conditions, the building has been designed with consideration given to corrosion, thermic isolation, impermeability and ventilation (Fig. 3).

The station occupies an area of aproximately $1100 \mathrm{~m}^{2}$ and is designed as primarily a single-storey complex with a tower (having two levels above, and one level below, ground). Processing and storage of sea water are located in the basement; on the second and third levels are the header tanks, equipment for cooling seawater, a library and conference room (Fig. 4).

In the entrance hall, local, hand-made crafts and other articles relating to the sea may be purchased at a "Marine Shop".

The public zone has a seating area, air-conditioning for use in summer, and soundabsorbent walls and floors. Special facilities are available for the differently-abled such as access ramps, WC, and a lift to the library or conference room.

In the Fishery Museum, originals and models of fishing gear and boats, as well as other utensils are to be displayed, explaining various methods of capture and fishprocessing (scale of 1:100, 1:10,1:1). This display will be completed by objects used in former and recent times such as harpoons, spears, hooks, fykenets, pots and nets.

The collection comprises items from nearly all the countries of Europe, as well as Angola, USA, Canada, South America, Greenland, Philippines and Japan. Occasional special displays about former whale-hunting in Madeira and the Azores, tuna-fishing and scientific diving will enhance the educational programme of the Station.

The Public Aquarium focusses on the local marine fauna and flora, particularly on those species of commercial interest for Aguda's small-scale fishery, including common invertebrates and macroalgae.

15 aquarium tanks with volumes of between 1200 and 6700 litres are supplied with cooled and filtered seawater by a semiclosed system. An average of 60 species of marine fishes and invertebrates will be maintained in an environment of controlled water temperature not exceeding $18^{\circ} \mathrm{C}$. 


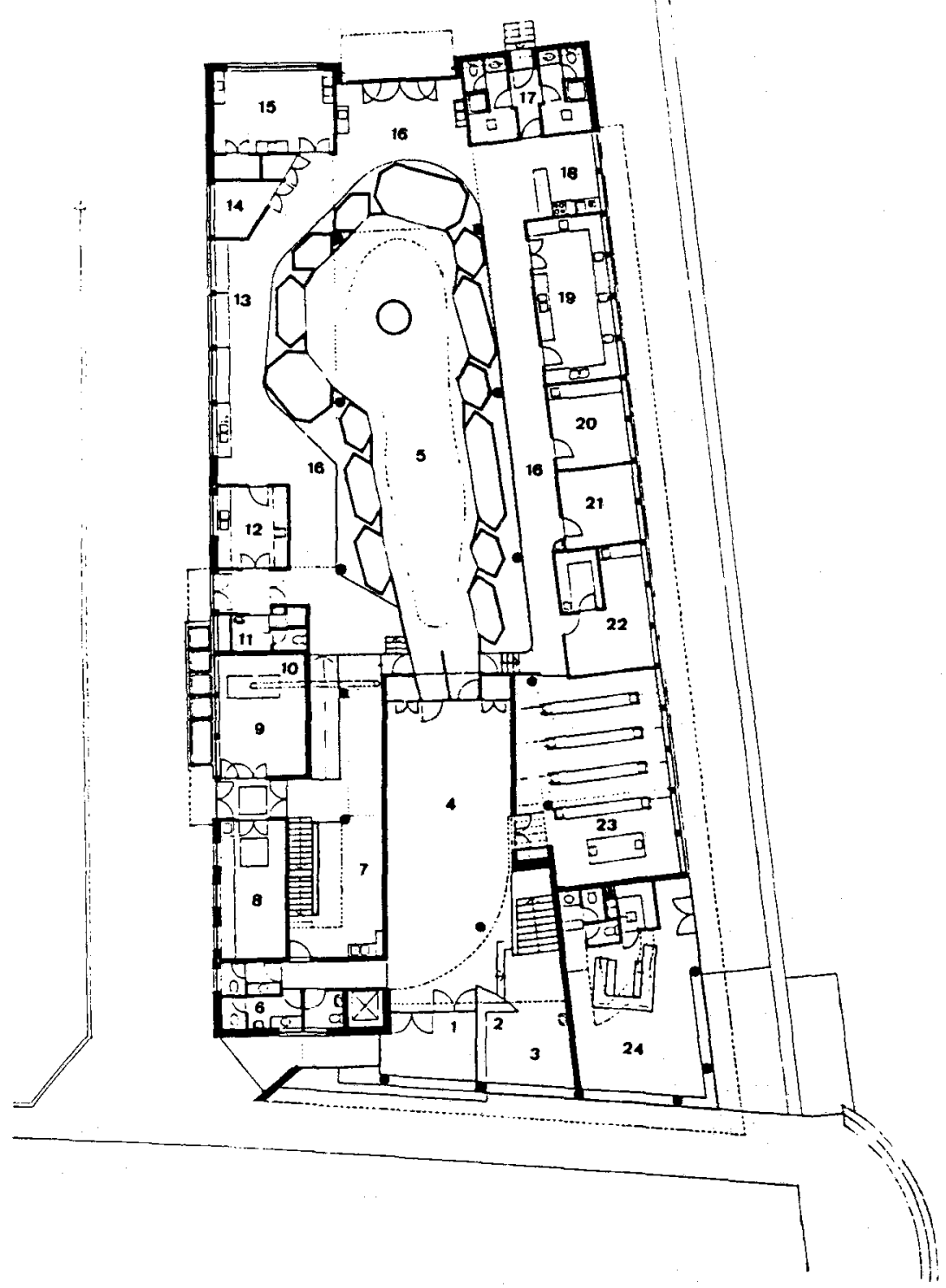

Fig. 2. Ground floor plan

$\begin{array}{llll}1 \text { - entrance } & 7 \text { - technical area } & 13 \text { - quarantine section } & 19 \text { - dry laboratory } \\ 2 \text { - ticket office } & 8 \text { - workshop } & 14 \text { - store room } & 20 \text { - laboratory } \\ 3 \text { - "Marine Shop" } & 9 \text { - compressor room } & 15 \text { - culture room } & 21 \text { - office } \\ \text { 4- Fishery Museum } & 10 \text { - generator room } & 16 \text { - service zone } & 22 \text { - photographic laboratory } \\ \text { 5- Aquarium } & 11 \text { - diving section } & 17 \text { - washrooms/staff } & 23 \text { - lecture room } \\ \text { 6- public WC's } & 12 \text { - wet laboratory } & 18 \text { - kitchen } & 24 \text { - cafeteria }\end{array}$



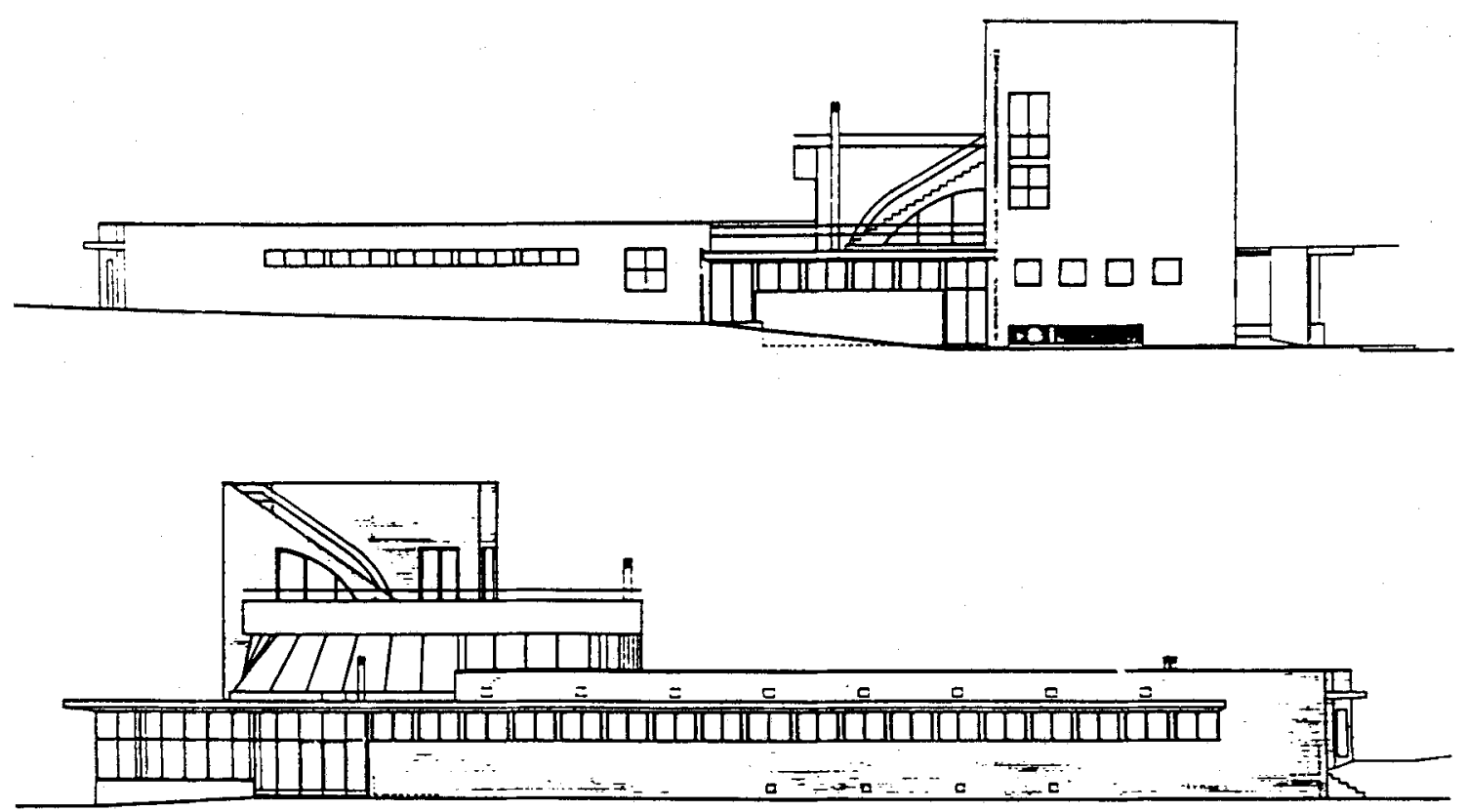

Fig. 3. External projections from East and West

Organisms will be captured with appropriate techniques and caution in collaboration with local fishermen. Aguda's fishing fleet permits easy access to the most representative marine biotopes of the area.

The display is designed to be selfguiding, from a rockpool exhibition in the upper intertidal zone, to the polychaete reefs in the lower zone; from algae fields and rocky caves in the sublittoral zone to sandbanks at greater depths, finally leading to the entrance of a small river estuary. The exhibits will display a true representation of Aguda's marine environment. Natural and synthetic materials will be used for the decoration, based on subaquatic photographs taken in the vicinity of the Station.

The information panels of the aquarium tanks are designed with enlarged slides, short texts, graphics and drawings, explaining the systematic identification of the species, their geographic distribution, reproductive cycle and other relevant biological or ecological aspects.

The Research and Educational Department will be concerned with scientific projects, programmes and services in marine biological disciplines, fishery biology and marine aquaculture. Special attention will be paid to control patterns of pollution and coast erosion.

The department consists of a wet- and dry laboratory, a diving and a quarantine section, a culture room, a photographic laboratory (annexed to a lecture room with work benches for practical studies), and a library and conference room. These areas are to be used by students, excursion groups, local researchers, guest scientists, fishermen and any other group of interested parties. 

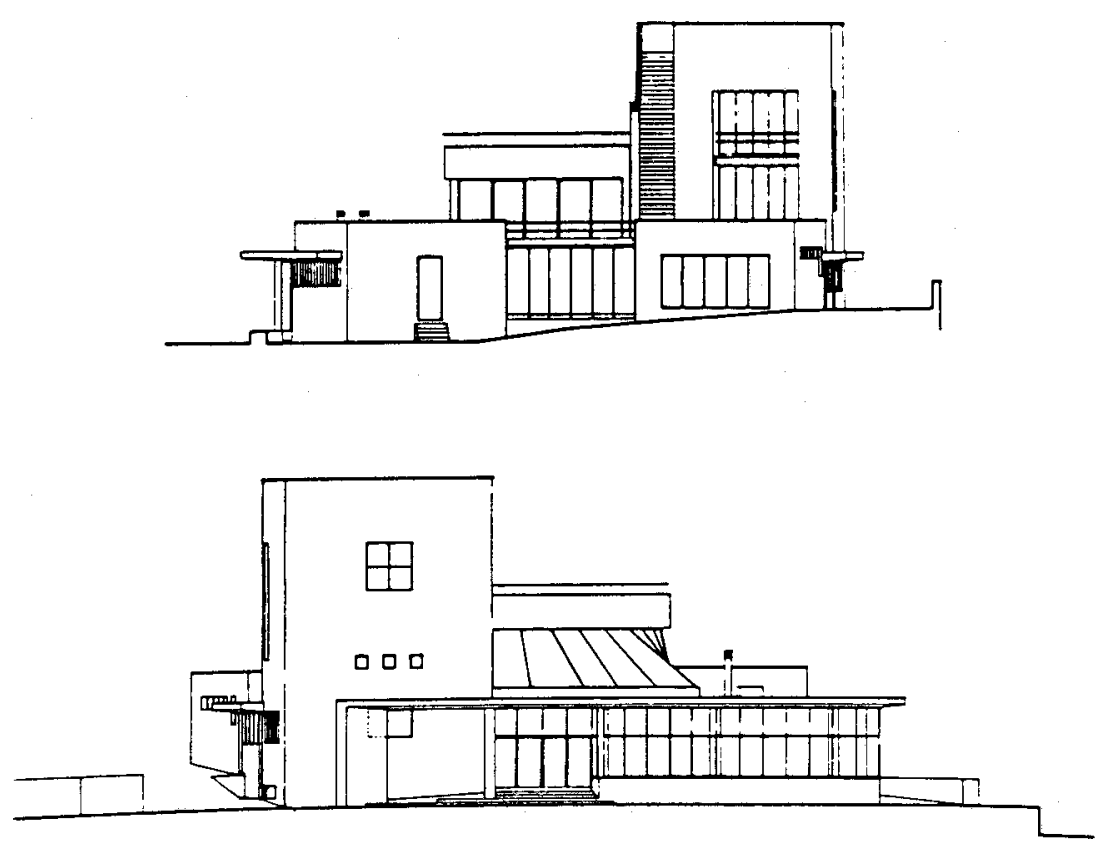

Fig. 4. External projections from South and North

In the outdoor area - near the main entrance to the service zone - fibreglass and concrete tanks are to be built for live-organism holding, and aquaculture experiments.

The service zone comprises a workshop, designed and equipped for all maintenance and experimental projects, and a kitchen and individual washrooms for the staff. A communication system allows contact between the administration office and the other main sections of the Station by individual lines.

The quarantine section is equipped with treatment facilities for the species to be exhibited and for live-food holding, rearing and refrigeration storage. The Aquarium supplies living and preserved aquatic animal samples to universities and secondary schools. The culture room serves to cultivate phyto- and zooplankton organisms for rearing marine fish larvae through their various growth stages.

In the photographic laboratory, all required work is to be carried out for the design of the information panels in the public zone and for the Research and Educational Department.

The library already contains a magnificient collection of basic volumes and international periodicals concerning fishery biology, fishing techniques and marine biological disciplines, based on the private library of Prof. Dr. Andres von Brandt.

The conference room serves to organize, coordinate and detail all projects relating to the maintenance, improvement and development of Aguda's small-scale fishery. 


\section{SEAWATER RE-CIRCULATION SYSTEM AND OTHER CRITERIA OF DESIGN}

The aquarium operates with a semiclosed system, because it is anticipated that the adjacent seawater will not be of adequate quality all year round. Storage, sedimentation, biological filtration, protein-skimming and sterilization are therefore necessary.

The choice of the circulation system was based on the following criteria:

- necessity for a simple and efficient renewal of sea water;

- availability of a closed circuit in event of poor external water quality and of an open circuit in event of good quality;

- availability of different water temperatures, facilitating the cooling process in the summer months;

- supply to the laboratories, lecture and culture rooms, easy cleaning of aquarium tanks and filters by backwashing from the open circuit;

- sufficient storage volume in the reservoirs for the closed circuit.

Because of the Station's position in front of the sea, a direct salt water supply is possible by an open intake, located in a protected, rocky area under the mean level at low tide. Pumps will operate during high tide to fill a sequence of reservoirs installed in the basement.

The reservoirs have a solid waste removal system and the water is constantly aerated. The raw sea water can be processed by two highrate sandfilters and then integrated into the semiclosed circuit gradually.

From the reservoirs, the water is brought up to the header tanks on the second level of the tower by a pair of centrifugal plastic pumps through a main delivery pipeline, passing an ultraviolet sterilization unit and two graphite heat exchangers. The flow is gravity fed from the header tanks down to the display tanks, sedimentation tank, biological filters and reservoirs.

On the ground floor, the water is supplied to the aquarium tanks from ring-mains attached to the ceiling or walls, and control valves. The collecting and discharge mains are installed below the tanks or work benches connected to a system of drainage channeis. All floors are angled towards drainage points and channels. The discharge of the whole building is into the waste-water system of the village.

All piping is made of PVC isolated by neoprene. Major lines are flanged, minor ones are glued. All corrosive materials are coated with selected epoxy paints. The whole system provides easy access for cleaning, other maintenance, repairs, substitution, or future expansion.

The gravity-flow dual media filter systems contain gravel and pieces of crushed oyster shell. The filters are provided with aeration, and a backflush device; they can be disconnected from each other to operate independently.

Two bypasses are installed in the basement: one for a foam fractionation unit, the other for a pair of trickling filters, each filled with plastic "hedgehogs" providing large surface areas for aerobic biological carbon oxidation and nitrification.

The ratio between the storage and display volume is $1.5: 1$ and the turn-over rate is one display tank volume per hour. To avoid accumulation of low biodegradable substances, a certain amount of water will be replaced monthly.

Raw seawater, filtered and temperature-controlled seawater, freshwater, electrical power, oil-free low-pressure air and drainage points are available at many locations 
throughout the service-zone, including the research and educational areas. Double capacity of essential parts of the circuits is included in the design. A central alarm system monitoring all vital areas is maintained by a diesel-operated generator, in case of emergency. Earth leakage circuit breakers are installed in the power supply and all outlets have waterproof fittings.

The display tanks are made of reinforced fibreglass. A perforated bottom serves for internal biological filtration by airlifts. An integrated overflow system takes the water either into the closed circuit or into a drainpipe from the open circuit to be discharged out of the system.

In case of infection, local therapy, necessity for a different temperature, etc., each tank can be disconnected from the circuit. Smaller aquarium tanks in the quarantine section or in the laboratories have their own water-processing equipment.

A combination of halogen vapour high-pressure lamps, units of different coloured fluorescent tubes and low tension halogen spotlights are used to iluminate the exhibits.

Two compressors providing high volume flows of low pressure oil-free air are mounted in a sealed room near to the workshop. Aeration takes place in all reservoirs, header tanks, biological filters, and in the aquarium tanks, as well as in the holding units of the Research and Educational Department. A constant dry air-flow prevents condensation on the glass panels of the display tanks in the public zone.

\section{THE ROLE OF AGUDA'S LITTORAL STATION AND FUTURE DEVELOPMENT}

The Station will offer a variety of programmes and services. Undergraduate and postgraduate training of students in marine biology disciplines and fishery management by invited guest scientists, seminars for secondary school teachers and the organization of specialized working groups are major aims of the educational programme.

The Station will undertake biological surveys to detect long-term changes of the shore ecology such as zonation patterns, species richness, distribution and density. Monitoring will be indispensible to establish programmes for the protection and conservation of the marine environment and to allow an evaluation of the fishing potential of the area. With regard to these aspects, the scientific exchange between European universities is considered to be highly desirable.

The programmes consist of:

- monitoring of the commercial utilization of stocks under the control of local development and environmental factors;

- conservation and protection of unique, representative, but vulnerable areas of Aguda's Beach, for example Sabellaria Reefs;

- management of activities such as fishing, baitdigging, diving and other recreational use of the shore;

- environmental impact assessment because of the increasing introduction of domestic and industrial waste water.

Among the services offered are:

- provision of working facilities for local and visiting scientists;

- support for professional training courses for local fishermen;

- organization of excursions along the shoreline and at sea;

- support for pre-arranged excursions from foreign universities; 
- public education in an easy-to-understand way by teaching basic ecological principles for the protection and conservation of the marine environment;

- exhibition and sale of local handcraft items made by retired fishermen and their families.

Acknowledgements. The author would like to express his sincerest thanks to the town council of Vila Nova de Gaia, to Ms. Sheila Allum, Porto, for correction of the English version, and to the people of Aguda for their encouragement.

\section{LITERATURE CITED}

Weber, M., 1989. The aquarium of Porto, its past, present and future. - Bull. Inst. Océanogr., Monaco (No. sp.) 5, 37-40.

Weber, M. \& Bleicker, D., 1991. Marés da Aguda - a pesca "artesanal" na praia da Aguda. Ediçōes Afrontamento, Porto, $223 \mathrm{pp}$. 